\title{
Coeficiente de rugosidade de Manning para o rio Paracatu
}

\author{
G uilherme B. Lyra ${ }^{1}$, Roberto A. Cecílio ${ }^{2}$, Sidney S. Zanetti ${ }^{3} \&$ G ustavo B. Lyra ${ }^{4}$
}

\begin{abstract}
RESUMO
Pela teoria do escoamento em canais abertos, o coeficiente de rugosidade de Manning é um dos principais parâmetros para descrição da vazão sobre uma superfície. Uma das dificuldades da aplicação da equação de Manning é a definição do seu coeficiente de rugosidade em rios e canais, razão pela qual o presente estudo tem como objetivo, estimar o coeficiente de rugosidade de Manning para os períodos de vazão mínima e máxima média mensal, em alguns trechos do rio Paracatu, e propor um modelo baseado em redes neurais artificiais para estimar o coeficiente de rugosidade. 0 coeficiente foi determinado em função das características geométricas do canal (área molhada, raio hidráulico e declividade do canal) e das séries de vazão de seis postos fluviométricos do rio Paracatu. Utilizaram-se séries de vazão de 21 anos (1976-1996). 0 coeficiente de rugosidade não apresenta tendência (maior ou menor) em função apenas do período seco ou de cheia. As características da margem e do leito do rio influenciam diretamente nos valores de coeficiente de rugosidade. 0 modelo baseado em rede neural apresentou desempenho satisfatório, o que possibilita estimar o coeficiente de rugosidade em função da cota, vazão, declividade e do raio hidráulico do rio.
\end{abstract}

Palavras-chave: vazão, condutos livres, redes neurais artificiais

\section{Manning roughness coefficient for Paracatu river, Brazil}

\begin{abstract}
According to open channel draining theory, the Manning's roughness coefficient is one of most important parameters to describe surface flow. $O$ ne of the difficulties in applications of Manning's equation is the definition of its roughness coefficient in rivers and channels. Thus, the aims of this paper are to estimate the Manning's roughness coefficient for the periods of minimum and maximum mean monthly flow in some parts of Paracatu river and to propose a model based on artificial neural networks to estimate the roughness coefficient. The coefficient was determined in function of channel geometrical characteristics (wetted area, hydraulic radius and slope of the channel) and of the outflow series of six fluviometric stations of Paracatu river. Long-term series of 21 years (1976 - 1996) of outflow were used. The roughness coefficient does not show any tendency (up or down)as a function of the dry or overflow periods only. The characteristics of margin and watercourse of river influenced directly the roughness coefficient data. The model based on neural network showed satisfactory performance, which allow us to estimate the roughness coefficient as a function of the quota, slope and hydraulic radius of the river.
\end{abstract}

Key words: water flow, open channel, artificial neural networks

\footnotetext{
1 ICAT/UFAL, Cidade Universitária, Km 14 Rod. BR 104, Tabuleiro dos Martins, CEP 57072-970, Maceió, AL. Fone (82) 3214-1360. E-mail(s): gbastoslyra@yahoo.com.br; gblyra@gmail.com

2 CCA/U FES, Alto U niversitário s/n, C.P. 16, CEP 29500-000, Alegre, ES. Fone: (28) 3558-1823. E-mail: rcecilio@cca.ufes.br

${ }^{3}$ CEUNES/U FES, Rodovia BR-101 Norte, km 60, Bairro Litorâneo, CEP 29932-540, São Mateus, ES. Fone (27) 3312-1533. E-mail: ssz@bol.com.br

${ }^{4}$ DCA/IF/UFRRJ, Rodovia BR-465, km 7, CEP 23890-970 - Seropédica - RJ. Fone: (21) 2682-1128. E-mail: gblyra@gmail.com
} 


\section{INTRODUÇãO}

Para atender às necessidades crescentes de uso da água, torna-se necessária a caracterização hidrológica dos cursos d'água, estudo este importante para a estimativa de sua disponibilidade hídrica, do seu potencial energético, do controle de inundações e do dimensionamento de obras hidráulicas (Tucci, 2001), haja vista que só assim é possível implementar um sistema de gestão dos recursos hídricos em bases técnico-científicas; desta forma, é oportuno um acompanhamento contínuo das variáveis mais importantes que descrevem o comportamento hidrológico dos rios (Martoni \& Lessa, 1999b). A disponibilidade dos dados básicos tem sido fator limitante no uso de modelos hidrológicos já que, dificilmente, se dispõem de seções transversais dos cursos d'água, dados de nível, de vazão e, principalmente, de estimativas da rugosidade (Tucci, 1980).

A teoria do escoamento em canais abertos é frequentemente aplicada na modelagem hidrológica para determinação da vazão. Devido à simplicidade de sua forma e dos resultados satisfatórios em aplicações práticas, a equação de Manning para canais abertos é utilizada intensivamente na modelagem hidrológica de cursos d'água (Ab. Ghani et al., 2007). O coeficiente de rugosidade de Manning (n) é parâmetro fundamental para descrição da vazão sobre uma superfície (Li \& Zhang, 2001). O ajuste da rugosidade de cursos d'água a um modelo hidrodinâmico fornece informações relativas ao nível de água, vazão e a velocidade do escoamento em qualquer trecho (Martoni \& Lessa, 1999a, Ab. Ghani et al., 2007), porém uma das dificuldades da aplicação da equação de Manning é justamente a definição do valor do coeficiente de rugosidade do rio ou canal (Yépez et al., 2000); este pode ser determinado por valores médios observados em campo (Azmon, 1992; Martoni \& Lessa, 1999b; Julien et al., 2002; Vieira \& Silva, 2004; Ab. Ghani et al., 2007; López et al., 2007) ou em experimentos de laboratório (Almeida Neto et al., 2000; Wong \& Lim, 2006; Lyra et al., 2007). Em geral, os condutos sob pressão são circulares, com poucos tipos de rugosidade, ao passo que nos canais as formas variam de circulares a irregulares (cursos d'água naturais), sendo a determinação dos coeficientes de rugosidade fator que influencia nas fórmulas de cálculo da vazão mais complexas (Neves, 1989).

Alguns estudos foram conduzidos com o objetivo da determinação do coeficiente de rugosidade para cursos d'água naturais. Azmon (1992) determinou o valor de n para diversos trechos do rio Soreq, em Israel. No Brasil, Martoni \& Lessa (1999b) ajustaram valores de $\mathrm{n}$ para trechos do rio Paraná. O coeficiente de rugosidade para os maiores rios da Venezuela foi estimado por Yépez et al. (2000), enquanto López et al. (2007) avaliaram n para diversos rios com leito de cascalho e córregos de montanha em diversas regiões do mundo e Ab. Ghani et al. (2007) para rios com leitos arenosos da Malásia.

Friedrich \& Ota (2003) apresentaram os efeitos de alguns parâmetros e condições de contorno sobre os resultados de um modelo de escoamento fluvial bidimensional. Este trabalho se refere à análise de sensibilidade efetuada para verificar a influência de alguns parâmetros utilizados no modelo computacional sobre o campo de velocidades e sobre os valores dos níveis de água e de velocidades resultantes. Estudou-se, isoladamente, a influência de três itens: coeficiente de viscosidade de torvelinho ("eddy viscosity"), condição de contorno na entrada do modelo (vazão) e coeficiente de rugosidade do leito do rio.

Em estudos hidrológicos é interessante determinar os valores extremos dos parâmetros avaliados como, por exemplo, para determinação das vazões mínimas e de referência para outorga (Silva et al., 2006). Os extremos são obtidos por análises probabilísticas, que permitem definir seus períodos e magnitudes de ocorrência a diversos níveis de probabilidade, e seu tempo de retorno. Nas análises probabilísticas a técnica dos percentis vem sendo utilizada extensivamente na determinação das probabilidades de ocorrência de valores extremos devido, particularmente, à facilidade de aplicação e à consolidação desta técnica (Xavier \& Xavier, 1987).

A sub-bacia do rio Paracatu, situada no Médio São Francisco, drena uma área de aproximadamente $45.600 \mathrm{~km}^{2}$, a qual representa cerca de 7\% da área de drenagem da Bacia do São Francisco (Brasil, 1996). Da área de drenagem da sub-bacia do rio Paracatu, cerca de $92 \%$ se encontram no Estado de Minas Gerais, 5\% em Goiás e 3\% no Distrito Federal (Ferreira \& Euclydes, 1997); suas principais sub-bacias são, pela margem direita, a do rio da Prata, com $3.750 \mathrm{~km}^{2}$, e a do rio do Sono, com $5.969 \mathrm{~km}^{2}$; pela margem esquerda, as bacias do rio Escuro, com $4.347 \mathrm{~km}^{2}$, do rio Preto, com $10.459 \mathrm{~km}^{2}$ e a do Ribeirão Entre Ribeiros, com 3.973 km² (ANA, 2003). As vazões do Paracatu, que chegam ao rio São Francisco são, em média, da ordem de $220 \mathrm{~m}^{3} \mathrm{~s}^{-1}$, durante o período de seca, e de $800 \mathrm{~m}^{3} \mathrm{~s}^{-1}$ na época de cheia, o que representa um percentual de 40 e 38\%, respectivamente, da vazão do rio São Francisco, no posto fluviométrico de Cachoeira da Manteiga (Brasil, 1996).

Com base no exposto se propôs, no presente estudo, estimar os valores do coeficiente de rugosidade de Manning, para os períodos de vazão mínima média mensal e máxima média mensal, em diversos trechos do rio Paracatu e um modelo baseado em redes neurais artificiais para estimar o coeficiente de rugosidade.

\section{MATERIAL E MÉTODOS}

\section{Coeficiente de rugosidade de Manning}

A disponibilidade de dados fluviométricos para o rio Paracatu é reduzida e poucos são os postos fluviométricos que possuem séries históricas de dados de vazão. O número de postos cujos perfis transversais do rio são conhecidos, é ainda menor. O sistema HIDROWEB da Agência Nacional de Águas (ANA) disponibiliza dados de perfis transversais, séries históricas de vazão e cotas de nível de água para apenas seis postos fluviométricos do rio Paracatu (Figura 1).

Para representar o canal do rio Paracatu utilizaram-se cinco perfis transversais de postos fluviométricos de responsabilidade da ANA; assim, a extensão do rio Paracatu foi dividida em cinco trechos diferentes localizados entre dois postos fluviométricos consecutivos, sendo os valores do coeficien- 


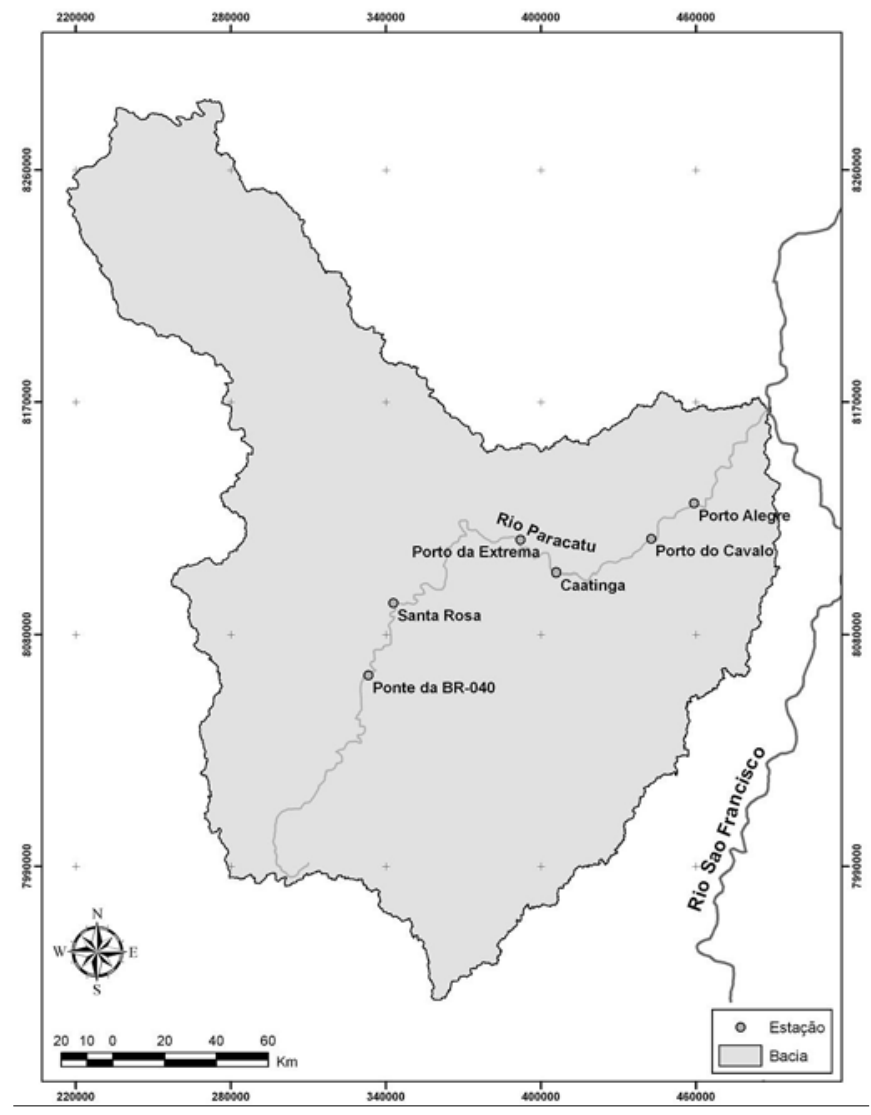

Figura 1. Bacia do rio Paracatu com os postos fluviométricos em destaque

te de rugosidade de Manning determinados para cada um dos trechos.

Obtiveram-se os valores de extensão de cada trecho por intermédio de mapas digitalizados (Brasil, 1996), com a utilização do software ArcView 3.2a. A declividade (I) de cada trecho foi estimada dividindo-se a diferença de nível entre os postos fluviométricos pela extensão do trecho de rio compreendido entre os mesmos (Tabela 1).

Tabela 1. Características dos trechos considerados ao longo do rio Paracatu

\begin{tabular}{|c|c|c|c|c|}
\hline Trecho & Estação de início & Estação de fim & Extensão (m) & Declividade $\left(\mathrm{m} \mathrm{m}^{-1}\right)$ \\
\hline$A-B$ & $\begin{array}{c}42290000 \\
\text { (Ponte da BR-040) }\end{array}$ & $\begin{array}{c}42395000 \\
\text { (Santa Rosa) }\end{array}$ & 61.394 & $1,0 \times 10^{-4}$ \\
\hline$B-C$ & $\begin{array}{c}42395000 \\
\text { (Santa Rosa) }\end{array}$ & $\begin{array}{c}42690001 \\
\text { (Porto da Extrema) }\end{array}$ & 123.008 & $9,0 \times 10^{-5}$ \\
\hline$C-D$ & $\begin{array}{c}42690001 \\
\text { (Porto da Extrema) }\end{array}$ & $\begin{array}{l}42750000 \\
\text { (Caatinga) }\end{array}$ & 20.410 & $1,5 \times 10^{-4}$ \\
\hline D-E & $\begin{array}{l}42750000 \\
\text { (Caatinga) }\end{array}$ & $\begin{array}{c}42930000 \\
\text { (Porto do Cavalo) }\end{array}$ & 159.632 & $1,0 \times 10^{-4}$ \\
\hline$E-F$ & $\begin{array}{c}42930000 \\
\text { (Porto do Cavalo) }\end{array}$ & $\begin{array}{c}42980000 \\
\text { (Porto Alegre) }\end{array}$ & 52.494 & $2,5 \times 10^{-4}$ \\
\hline
\end{tabular}

Estimaram-se os coeficientes de rugosidade, pela equação de Manning (Eq. 1), conhecendo-se os parâmetros geométri$\cos (\mathrm{A}, \mathrm{Rh}$ e I) e hidráulicos $(\mathrm{Q})$ de cada trecho; desta forma se obtiveram para cada um dos cinco trechos, dois valores de rugosidade por cada ano da série, sendo um de vazão mínima média mensal no período de seca e outro de vazão máxima média mensal no período de cheia.

$$
\mathrm{Q}=\frac{1}{\mathrm{n}} \mathrm{A} \mathrm{Rh}^{2 / 3} \mathrm{I}^{1 / 2}
$$

em que: Q - vazão escoada, $\mathrm{m}^{3} \mathrm{~s}^{-1} ; \mathrm{n}$ - coeficiente de rugosidade de Manning, $\mathrm{m}^{-1 / 3} \mathrm{~s} ; \mathrm{A}$ - área molhada, $\mathrm{m}^{2} ; \mathrm{Rh}$ - raio hidráulico, $\mathrm{m}$; I - declividade do canal, $\mathrm{m} \mathrm{m}^{-1}$

Determinaram-se, para todos os postos fluviométricos, as séries históricas de cotas do nível de água e de vazão no período de 1976 a 1996. Com os dados do perfil transversal do rio nos postos fluviométricos e a série histórica de cotas do nível da água, calcularam-se os seguintes parâmetros geométricos de cada trecho: área da seção transversal, perímetro molhado e raio hidráulico (Eq. 2); os referidos parâmetros foram determinados para cotas do nível da água correspondentes às vazões mínima e máxima média mensal, para cada ano da série, representado os períodos de seca e cheia do rio Paracatu, segundo classificação da ANA (2003), respectivamente.

$$
\mathrm{Rh}=\frac{\mathrm{A}}{\mathrm{P}}
$$

em que: $\mathrm{P}$ - perímetro molhado, $\mathrm{m}$.

Determinou-se a distribuição esperada dos percentis médios mensais dos coeficientes de Manning para os períodos de seca e cheia, utilizando-se todos os anos da série histórica a nível de probabilidade de $25 \%$, ou seja, avaliou-se a probabilidade de $75 \%$ de ocorrer um valor igual ou superior de $n$ para esses períodos. $\mathrm{O}$ percentil $\left(\alpha_{\mathrm{p}}\right)$ equivalente ao valor de uma variável contínua $(\mathrm{X})$, que corresponde a uma porcentagem da área sob a curva da função densidade de probabilidade (F), é definido como:

$$
\operatorname{Prob}\left(X \leq \alpha_{P}\right)=F\left(\alpha_{P}\right)
$$

Visando comparar os coeficientes de rugosidade do período de seca com os do período de cheia, aplicou-se o teste " $\mathrm{t}$ " $(\mathrm{p}<0,01)$ para cada trecho estudado.

\section{Modelagem do coeficiente de rugosidade por redes neurais artificiais}

O coeficiente de rugosidade médio mensal, tanto para o período de cheia quanto para o de seca, foi estimado por meio de uma rede neural artificial (RNA), em função dos valores médios mensais da cota, vazão, declividade e raio hidráulico. O conjunto de dados disponível totalizou 208 observações médias mensais, das quais 170 foram utilizadas para treinar a rede e 38 para testar o seu desempenho.

Utilizou-se uma rede neural artificial do tipo "perceptron" de múltiplas camadas (MLP, "multilayer perceptron"); nesse tipo de rede o sinal de entrada se propaga para frente ("feedforward"), camada por camada sendo, em seguida, retropropagado para a correção do erro (ajuste dos pesos sinápticos) (Hagan \& Menhaj, 1994; Zanetti et al., 2008); este procedimento é repetido por várias iterações até a finalização do treinamento.

Matematicamente, os neurônios que compõem a rede neural artificial podem ser descritos por: 


$$
\begin{gathered}
\mathrm{u}_{\mathrm{k}}=\sum_{\mathrm{j}=1}^{\mathrm{n}} \mathrm{w}_{\mathrm{k}, \mathrm{j}} \cdot \mathrm{x}_{\mathrm{j}} \\
\mathrm{v}_{\mathrm{k}}=\mathrm{u}_{\mathrm{k}}+\mathrm{b}_{\mathrm{k}} \\
\mathrm{y}_{\mathrm{k}}=\mathrm{f}\left(\mathrm{v}_{\mathrm{k}}\right)
\end{gathered}
$$

em que: $\mathrm{u}_{\mathrm{k}}$ - saída do combinador linear; $\mathrm{w}_{(\mathrm{k}, 1)}, \mathrm{w}_{(\mathrm{k}, 2)}, \ldots, \mathrm{w}_{(\mathrm{k}, \mathrm{n})}$ - pesos sinápticos; $\mathrm{x}_{1}, \mathrm{x}_{2}, \ldots \mathrm{x}_{\mathrm{n}}$ - sinais de entrada; $\mathrm{v}_{\mathrm{k}}$ - potencial de ativação; $\mathrm{b}$ - bias; $\mathrm{y}_{\mathrm{k}}$ - sinal de saída do neurônio k; $\mathrm{f}\left(\mathrm{v}_{\mathrm{k}}\right)$ - função de ativação. No neurônio presente na camada de saída da rede o coeficiente de rugosidade estimado corresponde ao seu respectivo sinal $\mathrm{y}_{\mathrm{k}}$.

A RNA foi treinada de forma supervisionada com o algoritmo de Levenberg-Marquardt o qual utiliza, para aproximação do mínimo da função de erro, o método de Newton (Hagan \& Menhaj, 1994).

$$
E Q M=\frac{\sum_{i=1}^{n}\left(Y_{0}-Y e\right)^{2}}{n}
$$

em que: EQM - erro quadrado médio, $\mathrm{m}^{-1 / 3} \mathrm{~s} ; \mathrm{n}$ - número de observações; Yo - coeficiente de rugosidade observado, $\mathrm{m}^{-1 / 3}$ $\mathrm{s}$; Ye - coeficiente de rugosidade estimado pela rede neural artificial, $\mathrm{m}^{-1 / 3} \mathrm{~s}$.

Tal algoritmo foi selecionado em virtude de sua superioridade em relação aos outros algoritmos comumente utilizados (i.e. "back-propagation") (Hagan \& Menhaj, 1994).

Como critério para encerrar o treinamento utilizou-se o método de treinamento com parada antecipada (Haykin, 2001), através do qual foi possível identificar o início do excesso de treinamento por meio do uso da validação cruzada; para tanto, os dados de treinamento foram divididos em dois subconjuntos, sendo um de estimação e outro de teste. O subconjunto de estimação foi utilizado para treinar a rede sendo que, após cada iteração, a seção de treinamento era interrompida visando realizar a validação cruzada. Quando o EQM do subconjunto de teste se apresentava menor que seu valor na iteração anterior, o treinamento da rede era continuado; caso contrário, o treinamento era finalizado pois, segundo Haykin (2001), o que a rede "aprende" após este ponto é essencialmente ruído contido nos dados de treinamento, ocasionando perda na habilidade de generalização entre padrões de entrada-saída similares.

Visando selecionar uma RNA que proporcionasse o melhor desempenho, efetuou-se um estudo prévio no qual se realizaram vários testes, variando-se o número de camadas ocultas, o número de neurônios e a função de ativação em cada camada; para cada combinação dessas características a rede foi treinada e testada (Zanetti et al., 2007; 2008), o que possibilitou a escolha da melhor RNA para estimar o coeficiente de rugosidade. A camada de saída da rede foi predefinida com apenas um neurônio e função de ativação do tipo linear.

Todos os cálculos referentes à construção, treinamento e teste das RNAs, foram efetuados no ambiente de programação do software MATLAB (Versão 6), sendo utilizados os recursos de sua caixa de ferramentas destinada à implementação de redes neurais ("Neural Network Toolbox" - Versão 4).

\section{Avaliação dos resultados da rede neural}

Após o processo de treinamento da RNA e com o conjunto de dados destinado para teste, os valores do coeficiente de rugosidade foram estimados e comparados com os valores observados.

Para verificar a qualidade do ajuste aplicou-se a análise de regressão linear simples $\left(\mathrm{Y}=\mathrm{b}_{\mathrm{o}}+\mathrm{b}_{1} \mathrm{X}\right)$, e se consideraram, como variáveis independentes $(\mathrm{X})$ os valores observados do coeficiente de rugosidade e, como variáveis dependentes (Y), os valores estimados com a rede neural. Os resultados foram analisados por meio dos coeficientes $\left(b_{o}, b_{1}\right.$ e $\left.r^{2}\right)$ das equações. O teste " $t$ " foi utilizado para avaliar estatisticamente o valor do intercepto $\left(\right.$ Ho: $\left.b_{o}=0\right)$ e da inclinação da reta (Ho: $\left.\mathrm{b}_{1}=1\right)$ a $\mathrm{p}<0,01$.

Adicionalmente e visando quantificar o grau de ajustamento entre os valores observados e estimados, calculou-se o índice de desempenho (c) proposto por Camargo \& Sentelhas (1997), o qual é resultante da multiplicação entre o coeficiente de concordância (d) proposto por Willmott (1981) e o coeficiente de correlação (r). O índice c é um valor adimensional, variando entre 0 e 1 , em que o valor 1 representa o completo ajustamento, enquanto o valor 0 indica o oposto.

\section{RESULTADOS E DISCUSSÃO}

Apresentam-se, na Tabela 2, os percentis de $25 \%$ de probabilidade $(\mathrm{p}<0,25)$ para os coeficientes de rugosidade de Manning estimados para cada trecho do rio Paracatu, nos períodos de vazão mínima média mensal e máxima média mensal, para a série de 1976 a 1996. Espera-se que, a 75\% de probabilidade, os coeficientes de rugosidade sejam superiores a 0,0119 (trecho D-E) e a 0,0594 (trecho C-D), no período de seca e maiores que 0,0178 (trecho D-E) e que 0,0369 (trecho E-F), no período de cheia. Esses intervalos do coeficiente de rugosidade se encontram próximos dos obtidos por Azmon (1992) para as partes mais planas do rio Soreq, em Israel $(0,025-0,126)$, aos determinados por Martoni \& Lessa (1999b), para alguns trechos também mais planos do rio Paraná $(0,0185$ - 0,0310) e aos observados para os grandes rios da Venezuela $(0,024-0,0625)$ por Yépez et al. (2000) e para rios com leito arenoso na Malásia $(0,024-0,345)$ por

Tabela 2. Percentis de $25 \%$ de probabilidade dos coeficientes de rugosidade de Manning de cada trecho do rio Paracatu, no período 1976-1996

\begin{tabular}{ccc}
\hline \multirow{2}{*}{ Trecho } & \multicolumn{2}{c}{ Coeficiente de rugosidade de Manning $\left(\mathbf{m}^{-1 / 3} \mathbf{s}\right)$} \\
\cline { 2 - 3 } & Período de seca & Período de cheia \\
A-B & 0,0171 & 0,0196 \\
B-C & 0,0365 & 0,0272 \\
C-D & 0,0594 & 0,0285 \\
D-E & 0,0119 & 0,0178 \\
E-F & 0,0200 & 0,0369 \\
\hline
\end{tabular}

${ }^{1}$ Conforme descrito na Tabela 1 

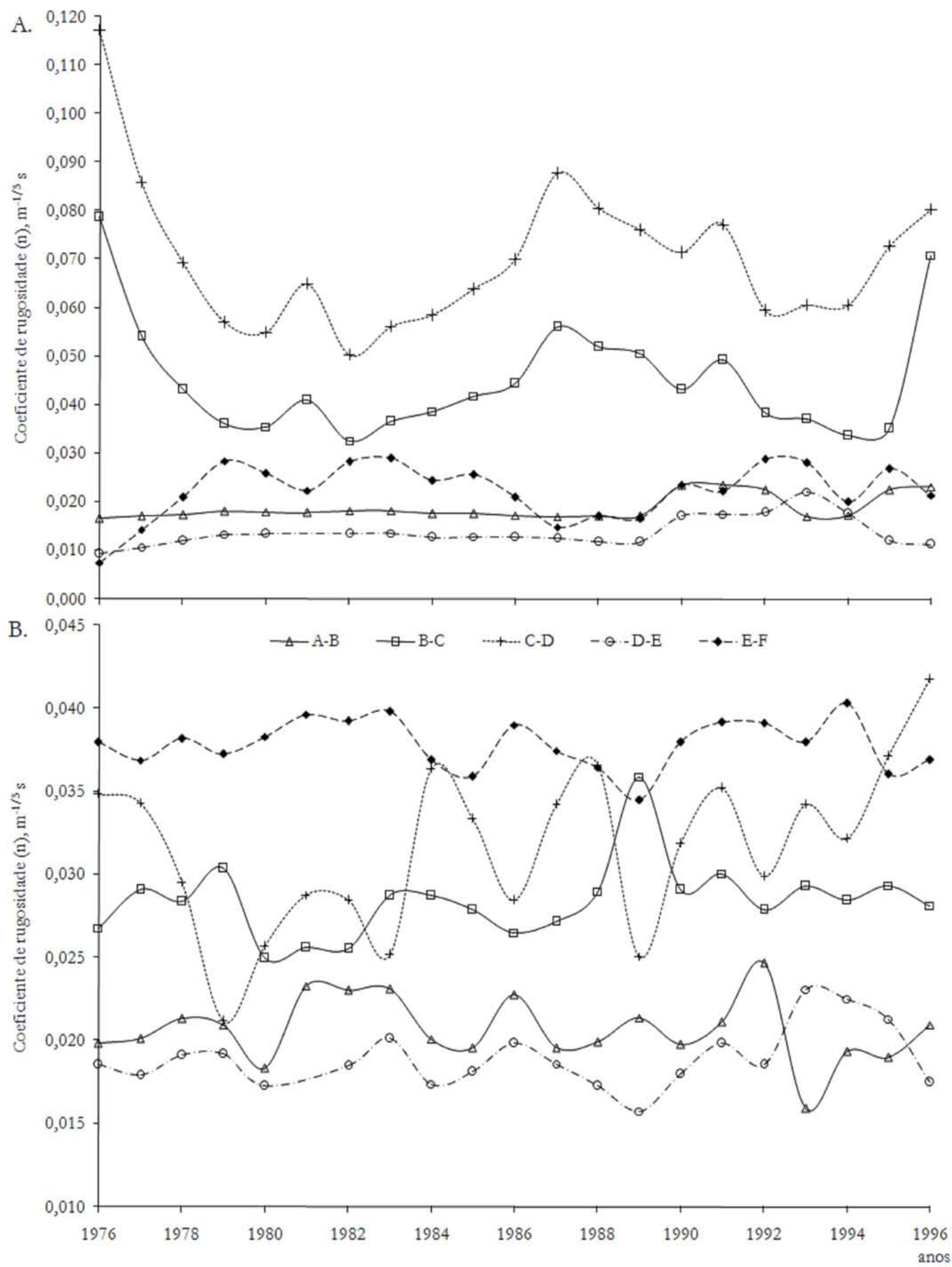

Figura 2. Variação anual do coeficiente de rugosidade no período de seca (A) e no período de cheia (B) entre os anos de 1976 e 1996

R. Bras. Eng. Agríc. Ambiental, v.14, n.4, p.343-350, 2010. 
Ab Ghani et al. (2007). A exceção foi o trecho D-E, no período de seca, com $n$ inferior.

De acordo com o teste "t", nos trechos A-B, D-E e E-F os coeficientes de rugosidade apresentaram diferenças estatísticas significativas $(\mathrm{p}<0,05)$ entre os períodos de cheia e seca, sendo maiores no período de cheia. De forma análoga, nos trechos B-C e C-D as diferenças foram estatisticamente significativas ( $\mathrm{p}<0,05)$; contudo, a tendência foi inversa, ou seja, os coeficientes de rugosidade foram maiores no período de seca.

Friedrich \& Ota (2003) concluíram, utilizando simulação computacional, que o aumento da rugosidade com a redução da profundidade traduz a maior resistência ao escoamento existente junto às margens do rio; este aumento, no entanto, é compensado pela redução da rugosidade no centro da seção transversal, onde a profundidade é geralmente maior, de modo que o perfil da superfície livre ao longo do eixo do rio não se altera significativamente entre uma simulação e outra.

Para Chow (1994), na maior parte dos escoamentos o valor de $\mathrm{n}$ diminui com o aumento do nível da água e da vazão visto que, quando a lâmina d'água é baixa, a irregularidade do fundo do canal está exposta ao seu efeito, aumentando o efeito da rugosidade; assim sendo, é de se esperar maiores valores de n no período de seca que no período de cheia do rio, como observado para os trechos B-C e C-D; entretanto, os trechos A-B, D-E e E-F do rio Paracatu apresentaram padrão inverso, isto é, o valor de n foi maior no período de cheia, fato também observado por Lane (1951), no rio Irawadi (Birmânia).

A explicação para esta tendência se deve ao fato de que, quando o nível de água é mais alto, a calha do curso d'água atinge áreas com maior cobertura vegetal ou que sejam mais rugosas e, quando a vazão é muito alta, o rio pode transbordar e parte do escoamento acontecer em uma planície inundada. Em geral, o valor de n para planícies inundadas é muito maior que a do curso em si e sua magnitude depende das condições da superfície dessas planícies.

Na Figura 2 se apresenta a variação dos valores de $n$ nos períodos de seca e cheia, para cada trecho do rio Paracatu, ao longo dos anos em estudo. No período de seca (Figura 2A), os trechos B-C e C-D apresentaram tendência de variação similar e elevados valores de $\mathrm{n}\left(>0,0326 \mathrm{~m}^{-1 / 3} \mathrm{~s}\right)$, principalmente nos primeiros anos da série (1976 a 1978). Ressaltase que nesses anos as vazões mínimas foram significativamente abaixo da média histórica; então, a presença de materiais, como galhos e pedras no leito do rio, pode ter causado aumento da rugosidade desses trechos.

A rugosidade do trecho E-F mostrou tendência de variação inversa a B-C e C-D, isto é, quando observado aumento (diminuição) de n em B-C e C-D, E-F mostrou diminuição (aumento) nos seus valores. As menores amplitudes de n no período seco foram observadas nos trechos A-B $\left(0,007 \mathrm{~m}^{-1 / 3} \mathrm{~s}\right)$ e D-E $\left(0,013 \mathrm{~m}^{-1 / 3} \mathrm{~s}\right)$, enquanto em B-C e C-D as amplitudes foram de 0,046 e $0,067 \mathrm{~m}^{-1 / 3} \mathrm{~s}$, respectivamente.

Contrário ao observado no período de seca, na cheia (Figura 2B) os trechos B-C e C-D mostraram tendência de variação inversa. As rugosidades desses trechos foram inferio- res às de E-F, mas superiores às dos trechos D-E e A-B; este último resultado foi similar ao observado no período de seca. Os trechos C-D e E-F apresentaram padrão de variação análogo. Com exceção do trecho A-B, em que a amplitude de variação de $\mathrm{n}$ foi superior no período de cheia em relação ao de seca, os demais trechos mostraram tendência inversa, com amplitude de n superior no período de seca; a amplitude neste período variou de 0,009 (A-B) a $0,021 \mathrm{~m}^{-1 / 3} \mathrm{~s}(\mathrm{C}-\mathrm{D})$.

Selecionou-se, para estimação do coeficiente de rugosidade, a RNA que apresentou o melhor desempenho com a mínima configuração possível; tal rede foi constituída por uma camada de entrada (com quatro variáveis), uma camada oculta (com dez neurônios) e uma camada de saída com um neurônio. A função de ativação utilizada foi a sigmóide logística, sendo esta uma das funções propostas por Demuth \& Beale (2003); tal função foi selecionada por ter proporcionado o melhor resultado.

Apresenta-se, na Figura 3, a análise de regressão linear simples como indicativo do ajuste entre valores de rugosidade observados e os estimados por meio da rede neural artificial. Os valores da inclinação da reta $(1,052)$ e do intercepto $(0,002)$ não diferiram estatisticamente de 1 e 0 , respectivamente, pelo teste " $\mathrm{t}$ " $(\mathrm{p}<0,01)$. O coeficiente de determinação $(0,9834)$, e o índice de desempenho c $(0,9865)$, se apresentaram elevados, confirmando que a rede neural apresentou desempenho satisfatório ao estimar o coeficiente de rugosidade. O EQM relativo ao conjunto de dados de treinamento foi da ordem de $1,2 \times 10^{-6}$ enquanto o valor indicado em relação ao conjunto de dados de teste foi da ordem de $5,2 \times 10^{-6}$.

Adicionalmente, é apresentada, na Figura 4, uma comparação entre valores de rugosidade observados e estimados por meio da rede neural. De forma geral, as linhas do gráfico se situaram próximas umas da outras, o que demonstrou o bom desempenho da estimação, com tendência de variação similar.

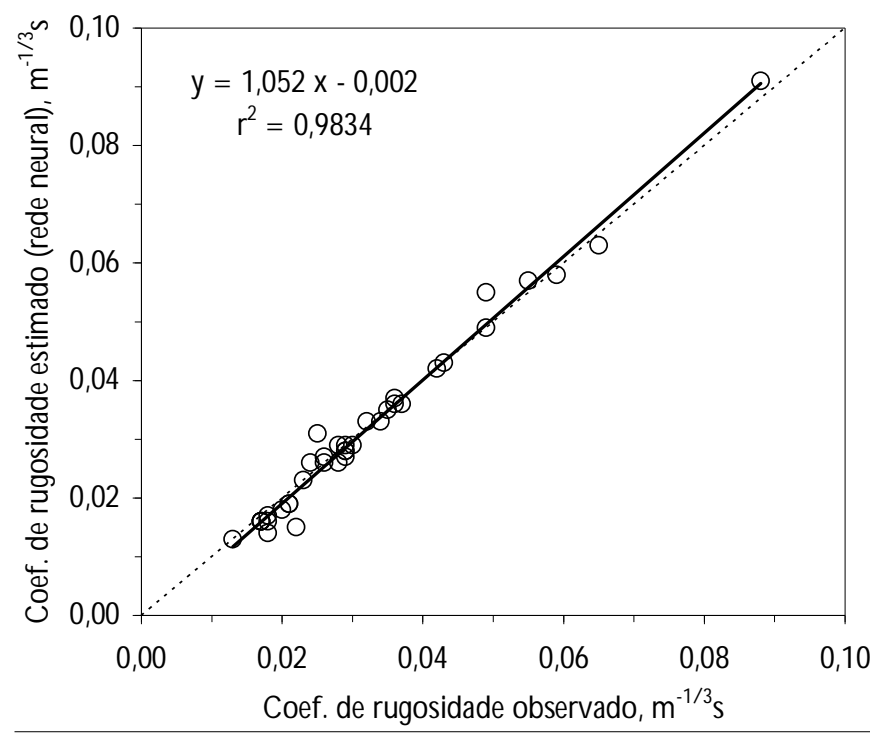

Figura 3. Regressão linear entre coeficiente de rugosidade observado e estimado pela rede neural 


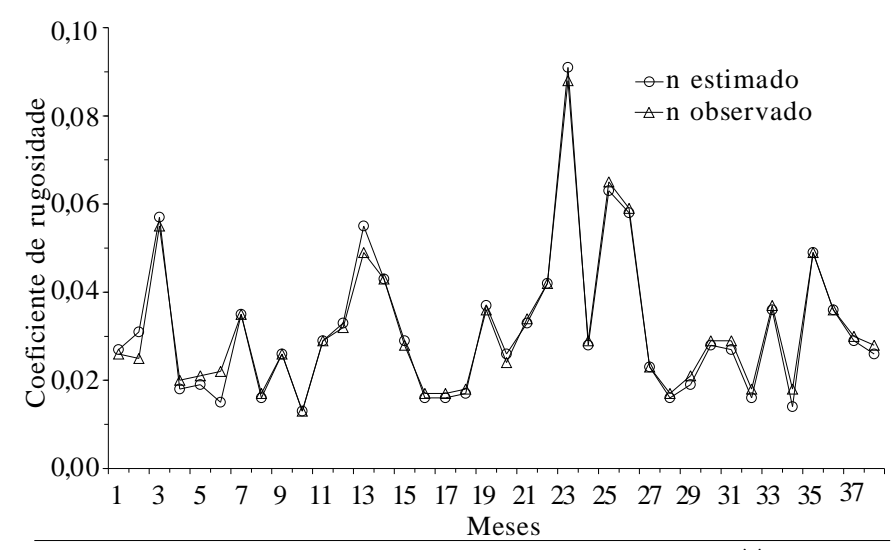

Figura 4. Comparação entre coeficientes de rugosidade de Manning (n) observados e estimados pela rede neural

\section{CONCLUSÕES}

1. O coeficiente de rugosidade de Manning não apresenta tendência de variação significativa (menor ou maior) apenas em função da época de cheia ou de seca, sendo dependente também das características da margem (árvores, galhos e pedras, dentre outros) e do leito do canal.

2. As características do leito do canal e da margem do rio Paracatu influenciam no coeficiente de rugosidade de Manning de forma diferenciada para cada trecho nos períodos de seca ou cheia.

3. O modelo baseado em rede neural mostra desempenho satisfatório, o que permite estimar o coeficiente de rugosidade em função da cota, vazão, declividade do rio e raio hidráulico do mesmo.

\section{LITERATURA CITADA}

Ab. Ghani, A.; Zakaria, N. A.; Kiat, C. C.; Ariffin, J.; Hasan, Z. A.; Ghaffar, A. B. A. Revised equations for Manning's coefficient for sand-bed rivers. International Journal River Basin Management, v.5, n.4, p.329-346, 2007.

Almeida Neto, J. A.; Testezlaf, R.; Matsura, E. E. Características hidráulicas de tubos de bambu gigante. Revista Brasileira de Engenharia Agrícola e Ambiental, v.4, n.1, p.1-7, 2000.

ANA - Agência Nacional de Águas. Memorial descritivo do cálculo da demanda humana de água contidas no documento "Base de referência do plano nacional de recursos hídricos". Nota Técnica 010/SPR/2003. Brasília: Superintendência de Outorgas da Agência Nacional de Águas, 2003. 30p.

Azmon, B. Manning coefficient of roughness - A case study along Soreq stream, 1971-1981. Journal of Hidrology, v.132, n.1-4, p.361-377, 1992.

Brasil - Governo Federal. Minas Gerais - Governo do Estado. Distrito Federal. Plano Diretor de recursos hídricos da bacia do rio Paracatu - PLANPAR. S.1.: 1996. v.1. T.1. CD-Rom.

Camargo, A. P.; Sentelhas, P. C. Avaliação do desempenho de diferentes métodos de estimativa da evapotranspiração potencial no Estado de São Paulo, Brasil. Revista Brasileira de Agrometeorologia, v.5, n.1, p.89-97, 1997.
Chow, V. T. Hidráulica de canales abiertos. Santafé de Bogotá: Mc Graw-Hill Interamericana S.A., 1994. 667p.

Demuth, H.; Beale, M. Neural network toolbox: For use with MATLAB. User's Guide Version 4.0, Natick: The Math Works, 2003.

Ferreira, P. A.; Euclydes, H. P. Recursos hídricos e tecnologia necessária aos projetos hidroagrícolas: Bacia do Paracatu. Viçosa: UFV, 1997. 200p.

Friedrich, M. F.; Ota, J. J. Modelagem computacional de escoamento fluvial: estudo de sensibilidade de parâmetros e condições de contorno. In: Simpósio Brasileiro de Recursos Hídricos, 15, 2003, Curitiba. Anais... Curitiba: Associação Brasileira de Recursos Hídricos, 2003. CD-Rom.

Hagan, M. T.; Menhaj, M. B. Training feedforward networks with the Marquardt algorithm. IEEE Transactions on Neural Networks, v.5, n.6, p.989-993, 1994.

Haykin, S. Redes Neurais: Princípios e prática. 2.ed. Porto Alegre: Bookman, 2001. 900p.

Julien, P. Y.; Klaassen, G. J.; Ten Brinke, W. B. M.; Wilbers, A. W. E. Case study: Bed resistance of rhine river during 1998 flood. Journal of Hydraulic Engineering, v.128, n.12, p.10421050, 2002.

Lane, E. W. Discussion on slope discharge formulae for alluvial streams and rives. Proceedings, New Zealand Institute of Engineers, v.57, p.435-438, 1951.

Li, Z.; Zhang, J. Calculation of field manning's roughness coefficient. Agricutural Water Management, v.49, n.2, p.153-161, 2001.

López, R.; Barragána, J.; Colomerb, A. Flow resistance equations without explicit estimation of the resistance coefficient for coarse-grained rivers. Journal of Hydrology, v.338, n.1-2, p.113-121, 2007.

Lyra, G. B.; Cecon, P. R.; Deniculi, W.; da Silva, D. D.; Oliveira, R. A. Determinação experimental dos coeficientes de rugosidade de Manning e Bazin em tubulações de PVC. Engenharia na Agricultura, v.15, n.4, 428-436, 2007.

Martoni, A. M.; Lessa, R. C. Modelagem hidrodinâmica do canal do rio Paraná, trecho Porto São José - Porto 18. Parte I: Caracterização física do canal. Acta Scientiarum, v.21, n.4, p.949-959, 1999a.

Martoni, A. M.; Lessa, R. C. Modelagem hidrodinâmica do canal do rio Paraná, trecho Porto São José - Porto 18. Parte II: Calibragem do modelo. Acta Scientiarum, v.21, n.4, p.961-970, 1999b.

Neves, E. T. Curso de hidráulica. 9.ed. São Paulo: Globo, 1989. $577 \mathrm{p}$.

Silva, A. M.; Oliveira, P. M.; Mello, C. R.; Pierangeli, C. Vazões mínimas e de referência para outorga na região do Alto Rio Grande, Minas Gerais. Revista Brasileira de Engenharia Agrícola e Ambiental, v.10, n.2, p.374-380, 2006.

Tucci, C. E. M. Hidrodinâmica de rios e canais. São Paulo: Departamento de Águas e Energia Elétrica/USP. 202p. 1980. Comunicação Técnica n.9.

Tucci, C. E. M. Hidrologia ciência e aplicação. Porto Alegre: Universidade/UFRGS: ABRH, 2.ed., 2001. 943p.

Vieira, D. B.; Silva, R. T. Estudo hidráulico de sulcos largos de infiltração. Irriga, v.9, n.2, p.193-206, 2004. 
Willmott, C. J. On the validation of model. Physical Geography, v.2, n.2, p.184-194, 1981.

Wong, T. S. W; Lim, C.K. Effect of loss model on evaluation of Manning roughness coefficient of experimental concrete catchment. Journal of Hydrology, v.331, n.1-2, p.205-218, 2006.

Xavier, T. M. B. S.; Xavier, A. F. S. Classificação e monitoração de períodos secos ou chuvosos e cálculo de índices pluviométricos para a região Nordeste do Brasil . Revista Brasileira de Engenharia Caderno de Recursos Hídricos, v.5, p.7-31, 1987.
Yépez, M. G. O.; Ventura, F. F. V.; Guevara, E.; Cartaya, H. Cálculo del coeficiente de rugosidad " $n$ " de Manning en los grandes ríos de Venezuela. Revista de la Facultad de Ingeniería, v.7, n.2, p.1-12, 2000.

Zanetti, S. S.; Sousa, E. F.; Carvalho, D. F.; Bernardo, S. Estimação da evapotranspiração de referência no Estado do Rio de Janeiro usando redes neurais artificiais. Revista Brasileira de Engenharia Agrícola e Ambiental, v.12, n.2, p.174-180, 2008.

Zanetti, S. S.; Sousa, E. F.; Oliveira, V. P. S.; Almeida, F. T.; Bernardo, S. Estimating evapotranspiration using artificial neural network and minimum climatological data. Journal of Irrigation and Drainage Engineering, v.33, n.2, p.83-89, 2007. 